\title{
Os temas e usos de interesse dos estudantes no livro didático de Física ${ }^{1}$
}

\section{The interesting themes and uses according to students in Physics textbooks}

\author{
Alysson Ramos Artuso*
}

\begin{abstract}
RESUMO
Há uma lacuna entre os estudos científicos brasileiros sobre materiais didáticos no que se refere a investigações de larga escala sobre o uso desses materiais em sala de aula e das preferências e opiniões de alunos e professores acerca deles. Por isso, o objetivo deste trabalho é identificar o interesse de estudantes brasileiros de Ensino Médio sobre 23 itens do livro de Física, bem como cotejar o resultado com pesquisas similares. Um questionário foi aplicado a 374 estudantes das cinco regiões brasileiras com possibilidade de comparação das respostas de acordo com os estratos da pesquisa, tais como sexo e idade do respondente. Exercícios de vestibular, do Exame Nacional do Ensino Médio (ENEM) e o funcionamento de produtos tecnológicos são os quesitos mais valorizados pelos discentes. Biografias, atividades em grupo e o contexto histórico em que se deram os desenvolvimentos científicos são os menos interessantes. Não houve diferenças frequentes entre os estratos pesquisados, mostrando certa homogeneidade sobre as preferências acerca do livro didático em todo o território nacional. Tais resultados têm potencial interesse também para docentes de Física, autores e editores de materiais didáticos, que podem focar seus trabalhos em temas mais adequados aos estudantes.
\end{abstract}

Palavras-chave: Manuais escolares. Ensino Médio. Pesquisa qualitative. Ensino de Física.

1 A pesquisa que está na origem desta produção recebe apoio financeiro do Instituto Federal do Paraná (IFPR) e do Conselho Nacional de Desenvolvimento Científico e Tecnológico (CNPq) com bolsas de iniciação científica destinadas aos estudantes Luis Henrique De Martino, Henrique Vieira da Costa e Leticia Lima, que contribuíram com esse projeto de pesquisa auxiliando na tabulação dos dados, construção dos gráficos e na realização de análises estatísticas.

* Instituto Federal de Educação, Ciência e Tecnologia do Paraná. Colombo, Paraná, Brasil. E-mail: alysson.artuso@ifpr.edu.br - http://orcid.org/0000-0003-0462-4382 


\begin{abstract}
There is a gap in the Brazilian scientific researches about textbooks regarding large-scale investigations of these materials uses in the classroom and the preferences and opinions of students and teachers about them. Therefore, the goal of this paper is to identify the interests according to the High School Brazilian students in 23 items of the Physics textbook, as well as compare the results with similar studies. A survey was applied to 374 students from five Brazilian regions with the possibility of comparing the answers according to the strata, such as the respondent's gender and age. Exercises from admission tests and National tests (ENEM), as well as the functioning of technological products are the most valued items by the students. Biographies, team tasks, and the historical context of the scientific developments are the least interesting. There were no often differences among the strata surveyed, showing some homogeneity about the textbook preferences throughout the Brazilian territory. These results has potential interest also to physics teachers, authors and publishers of learning materials, who can focus their work on themes more suitable for students.
\end{abstract}

Keywords: Physics textbooks. Secondary School. High School. Qualitative research. Physics teaching.

\title{
Introdução
}

Estudos científicos sobre livros didáticos podem ser justificados por diversos interesses, como os políticos, econômicos, culturais e pedagógicos. Politicamente, os manuais escolares servem como ferramenta para implementação de políticas públicas educacionais, por exemplo, na operacionalização de uma Base Nacional Curricular Comum, a qual eles devem seguir para ser aprovados no Programa Nacional do Livro Didático (PNLD). Na dimensão econômica, uma discussão posta é o impacto dos investimentos no PNLD - mais de um bilhão de reais anuais investidos na compra e distribuição das obras (BRASIL, 2019). Culturalmente, cabe discutir-se, por exemplo, o papel do livro didático na cultura escolar e as influências que sofre e exerce, bem como as práticas que estimula ou desfavorece. Do ponto de vista pedagógico, algumas das muitas questões envolvem sua adequação conceitual e metodológica, além dos usos e das preferências do livro didático por parte de professores e estudantes.

Embora sem desconsiderar as múltiplas faces do livro didático, é neste último ponto - de usos e preferências - que se concentra o amplo projeto do qual este trabalho faz parte. Assim, a presente investigação tem como objetivo 
levantar quais são, entre 23 itens, os mais e menos valorizados pelos estudantes nos livros didáticos de Física do Ensino Médio. Para isso, foi aplicado um amplo questionário anônimo, que teve por base estudos qualitativos anteriores, a 374 alunos de Ensino Médio das cinco regiões do país no período de 2012 e 2014.

Desse questionário, selecionou-se as questões que fornecem informações para caracterizar a amostra, como idade e rede de ensino (pública ou privada) do respondente e a pergunta "Classifique quais temas e usos mais despertariam teu interesse num livro didático de Física". Esta questão é composta de 23 itens para os alunos avaliarem. Alguns exemplos são "exercícios de vestibular", "conteúdo digital na internet associado ao livro", "uso de charges e tirinhas" e "experimentos simples".

Pegando o último item como exemplo, sua presença no livro didático foi entendida como indicativo do interesse dos estudantes pelo uso de experimentos, elemento possível de uma abordagem experimental. Isso, claro, não significa que o estudante vivenciou uma abordagem experimental em seu processo ensino aprendizagem, pois o livro pode conter experimentos de fácil realização e nunca o estudante executar o experimento, afinal, isso também depende de como estudantes e professores exploram o livro. Mas, como a presente pesquisa se restringe ao nível do interesse dos estudantes, entende-se que este é um exemplo de item que demonstra o interesse dos discentes sobre possíveis abordagens que decorrem dos temas e usos investigados pelo instrumento de pesquisa.

Para o ranqueamento dos interesses item a item e posterior comparação entre os diferentes subgrupos pesquisados, foram realizados testes de hipótese. Configura-se, assim, um estudo quantitativo de larga escala, mas articulado a pesquisas qualitativas prévias. Tal articulação é necessária, uma vez que as pesquisas qualitativas têm o mérito de olhar com profundidade vários aspectos da utilização e das preferências sobre os livros didáticos, entretanto, seus resultados não necessariamente são expansíveis para toda a população. Assim, o presente trabalho pretende, justamente, gerar resultados mais abrangentes para a área de pesquisa. Dessa forma, entende-se ser possível adquirir um maior conhecimento sobre os interesses dos estudantes e, assim, contribuir com o campo científico, mas também com o trabalho de docentes, autores e editores e mesmo elaboradores dos editais e avaliadores do PNLD.

Ressalta-se, contudo, que os resultados não se restringem e nem são aplicáveis somente aos livros aprovados no PNLD e, portanto, utilizados na maior parte da rede pública. Os achados da pesquisa dizem respeito também aos livros utilizados no mercado privado e podem ser considerados pelos pesquisadores do campo e pelo mercado editorial geral. 


\section{Fundamentação teórica}

Três princípios fundamentam a presente investigação. O primeiro deles é a compreensão dos manuais escolares como integrante da cultura escolar, segundo a linha de Forquim (1993). Nesse sentido, não se concebe que o processo educativo escolar esteja simplesmente subordinado a um conjunto de conteúdos e métodos presentes nos livros. Esse processo também inclui, entre outros, práticas e comportamentos que possibilitam e permeiam a disseminação e assimilação dos conteúdos e métodos. Por isso, para além da discussão da correção e adequação dos conhecimentos científicos presentes nos livros didáticos, cabe investigar os usos e relações que docentes e estudantes fazem ou têm com eles, incluindo as escolhas e preferências culturais e sociais expressas por esses atores (FORQUIM, 1993; APPLE, 2001; CHOPIN, 2004; GARCIA, 2009).

Em segundo lugar, reconhece-se esse material didático como dependente e multifacetado em relação às ações de docentes e estudantes. Assim como na metáfora do caleidoscópio, são múltiplos os resultados das imagens formadas a depender de como o artefato é manuseado pelos sujeitos escolares. Os valores, importâncias e relações estabelecidos são diversos e, portanto, a adoção de um mesmo livro didático não significa, por exemplo, um uso idêntico de estudantes e professores em localidades, escolas ou turmas diversas (ARTUSO, 2014; ARTUSO; APPEL, 2015; LEITE; GARCIA, 2017).

Exemplo vinculado a esses dois primeiros princípios teóricos - e central para a presente pesquisa - é o interesse dos alunos, certamente relacionado com suas cobranças e expectativas enquanto estudantes. Assim, os resultados encontrados devem ser discutidos e contextualizada diante desse viés, que não se desvincula do que é praticado nas escolas.

O terceiro princípio é compreender o livro como parte do mercado editorial, sujeito a interesses políticos e econômicos que podem ter primazia sobre os interesses pedagógicos. Assim, a despeito do que possam pensar autores e editores, antes de tudo, uma obra deve satisfazer as diretrizes impostas pelo Ministério da Educação (MEC) por meio do edital de seleção do PNLD. Nessa etapa relacionada com o edital e a avaliação das obras, é preciso reconhecer que há forte relação e participação da comunidade de pesquisa em educação em ciências, atuando como mediadora entre concepções que circulam na área e a produção dos livros didáticos. Porém, os autores e editores não necessariamente concordam com a visão de educação presente no edital. A autonomia autoral e editorial, entretanto, está sujeita a mais dois filtros, talvez os mais restritivos, que são as questões comerciais, tais como os custos de produção, e as decisões 
gerenciais de uma editora baseadas no comportamento do mercado e nas expectativas sobre ele. Condições materiais, como a escassez de tempo e remuneração de autores (que tipicamente só recebem alguma remuneração após a aprovação e comercialização da obra, o que lhes faz dividir o tempo de autoria com outras atividades profissionais, como o magistério), o número reduzido de profissionais no processo editorial das obras e os prazos apertados impostos pelos editais e pelas decisões gerenciais são outros exemplos de influências que compõem o resultado concreto do livro didático e podem contribuir para a concentração de $70 \%$ das vendas do PNLD nas mãos das grandes editoras, notadamente de três grupos: Santillana, Somos/Kroton e FTD (MUNAKATA, 2012; CASSIANO, 2013; ARTUSO, 2016; MARTINS; GARCIA, 2019; MEC, 2019). Para fundamentar a pesquisa, tomou-se por base as investigações quantitativas e qualitativas relatadas a seguir. Elas forneceram um modelo de perguntas a serem feitas aos estudantes, bem como uma base de resultados, ainda que de abrangência local, para futura comparação. É a partir delas que se montou o questionário utilizado e é primeiramente com elas que os resultados de larga escala serão comparados. Vale ressaltar que, no período de elaboração da pesquisa, que se iniciou em 2012, eram escassas as investigações com estudantes sobre livros de Física, daí a extensão a disciplinas correlatas e pesquisas também com docentes.

Em pesquisa sobre livros de Química, mas cujos resultados supõem-se válidos para discutir-se o caso da Física, Carneiro, Santos e Mól (2005) investigaram a opinião docente sobre os manuais escolares. Entre os aspectos positivos citados pela maioria dos professores estão a diversidade de temas do cotidiano, estrutura física do livro e linguagem. Ainda segundo a maior parte dos docentes, os alunos também se interessam por ilustrações atrativas, material em formato de revista e experimentos fáceis de realizar. As abordagens da relevância tecnológica e social e do contexto histórico dos conteúdos presentes nos livros didáticos receberam tanto elogios quanto críticas dos professores.

Em Garcia (2009) e Garcia, Garcia e Pivovar (2007), são relatadas entrevistas e a aplicação de questionários com sete professores de uma escola curitibana sobre usos e preferências do livro didático. Entre outros resultados, os professores mais experientes apontaram o desejo por livros com linguagem menos formal, com problemas-desafio, situações cotidianas, experimentos de fácil manuseio e que mostrem o processo de construção dos conhecimentos. Professores iniciantes destacaram o interesse apenas por enfoques conceituais.

Também em Megid Neto e Fracalanza (2003), em pesquisa com professores de Ciências, identificaram as atividades experimentais de fácil realização como desejo docente, entre outras características de interesse, tais como ilustrações atraentes e isenção de preconceitos socioculturais. 
Em pesquisa sobre o ensino de Física, o livro didático e a prática docente, Wuo (2002, p. 164) argumenta que o livro didático "pode sugerir atividades complementares, apresentar soluções variadas e estimuladoras que favoreçam uma aprendizagem mais criativa, trazendo situações do cotidiano, explicações de fenômenos interessantes, apresentação de tópicos mais avançados, resolução de problemas mais elaborados, etc."

Quanto a pesquisas similares, tem-se, no cenário internacional, a investigação de Dake (2007), que pesquisou os interesses de estudantes americanos ingressantes no Ensino Superior sobre alguns atributos dos livros didáticos de Física. Entre suas descobertas, exemplos do cotidiano estavam entre os aspectos mais valorizados, enquanto anexos ao livro, como materiais digitais e links a websites não eram valorizados pelos alunos.

Também Nogova (2011), em estudo com alunos europeus de Ensino Médio, identificou os livros digitais, assim como os exercícios de recapitulação, entre os aspectos menos desejados pelos estudantes. No outro polo, textos curtos com imagens foram a principal preferência.

No cenário brasileiro, Mello (2013) fez um levantamento com duas turmas de recém-formados do Ensino Médio de diferentes escolas de Curitiba. A pesquisadora constatou que as características de maior interesse dos alunos são a clareza, a organização do conteúdo e a possibilidade de autonomia nos estudos propiciada pelo livro didático. Na comparação entre alunos de diferentes redes, os estudantes da rede privada declararam um baixo interesse por discussões do contexto histórico do conhecimento científico e pela presença de experimentos de fácil realização nos manuais escolares em comparação com os estudantes da escola pública.

Em Paranaguá/PR, Dias da Silva e Portela (2018) também fizeram uma investigação sobre os usos e preferências do livro didático de Física, abrangendo 189 estudantes de Ensino Médio. Entre os aspectos mais valorizados no livro estavam as imagens e a quantidade e qualidade dos exercícios. A abordagem do cotidiano e a proposição de experimentos tiveram um número baixo de citações, com apenas duas respostas cada.

Como visto, as pesquisas nacionais citadas, mesmo quando possuem caráter quantitativo, são restritas a uma localidade, sem pretensão de generalização dos resultados. É justamente com essa lacuna no campo de pesquisa que o presente projeto pretende contribuir. Além disso, outras perguntas do mesmo questionário, com resultados já publicados (ARTUSO et al., 2019), também podem auxiliar na discussão do presente artigo. Em especial, já se identificou que os estudantes brasileiros valorizam, em uma escala de 0 a $100 \%$, a ausência de erros conceituais 
(87\%), a presença de resumos e esquemas (80\%) e livros de Física com temas capazes de despertar seus interesses $(75 \%)$. Identificar quais seriam esses temas não foi objeto de estudo daquele trabalho, mas é o objetivo deste.

\section{Metodologia}

O desenho de pesquisa é o de uma investigação descritiva exploratória, na qual se objetiva levantar quais os temas e usos mais e menos valorizados pelos estudantes nos livros didáticos de Física do Ensino Médio e, assim, caracterizar um panorama geral com potencial de gerar novas questões e hipóteses a serem testadas e aprofundadas em estudos futuros de caráter explicativo e associativo (GRESSLER, 2004). Para isso, empregou-se uma análise estatística inicialmente descritiva e uma posterior de inferência, na qual foram realizados testes de hipótese.

Para cumprir com os objetivos propostos, desenvolveu-se um survey de desenho interseccional (isto é, de corte temporal transversal, no qual não se analisam eventuais mudanças na opinião dos respondentes ao longo do tempo, mas apenas se registra o ocorrido em certo instante) tomando-se como base os itens trabalhados pelos estudos qualitativos de Carneiro, Santos e Mól (2005), Garcia (2009), Garcia, Garcia e Pivovar (2007), Megid Neto e Fracalanza (2003) e Wuo (2002). Perguntas realizadas pelos pesquisadores ou comentários efetuados por professores ou estudantes nessas pesquisas foram utilizados para compor os itens de investigação do survey.

Após três rodadas de testes-pilotos feitos para verificar a adequação da linguagem, vieses e sobreposições nas perguntas, os questionários foram aplicados a 374 alunos do Ensino Médio das cinco regiões do país a partir do envio eletrônico após contato prévio do pesquisador. Diante de um universo de quase sete milhões de estudantes, essa amostragem fornece, ao nível de significância de $95 \%$, um erro máximo de 5,07\% nas respostas.

A coleta dos dados se deu entre 2012 e 2014 e, para a seleção dos respondentes, contactou-se por e-mail todas as secretarias estaduais de educação e diversos sindicatos e programas de pós-graduação em busca de dados de número de escolas e contatos em cada estado. Assim, levantou-se o contato de escolas e foi realizado um sorteio proporcional ao número de escolas por região de acordo com o Censo Escolar de 2010. Mais de três mil contatos foram tentados, todos por e-mail. Era pedido para o contato na escola divulgar o link 
da pesquisa entre os estudantes e, como resultado típico nenhum, um ou muito poucos estudantes por escola respondiam - o que pode ser verificado no banco de dados da pesquisa, embora anônimo e sem perguntar o nome da escola, pela dispersão de municípios e diferenças nas datas das respostas.

Embora se tenha buscado formar uma amostra representativa da população brasileira, o critério da conveniência foi adotado para a região Norte em razão do baixo número de respostas, aproveitando-se da viagem de um colaborador para a região e a aplicação do questionário em um encontro de professores, com o pedido de que eles também divulgassem o link para a versão dos estudantes em suas turmas. Embora isso enfraqueça a extensão da pesquisa como representativa de toda a população, tal procedimento não a invalida por completo, e sua pertinência pode vir a ser confirmada na comparação com levantamentos similares (BOLFARINE; BUSSAB, 2005). Por ora, não se detectou pesquisas em larga escala com materiais de Física no cenário brasileiro.

A análise principal se concentrou na questão: "Classifique quais temas e usos mais despertariam teu interesse num livro didático de Física" presente no amplo questionário do projeto. Primeiro é preciso explicitar a razão da pergunta usar os termos temas e usos. Na busca por uma linguagem acessível aos estudantes, essas foram as palavras escolhidas para se referir ao caso do livro abarcar assuntos tais como situações do cotidiano ou relações com a natureza e o meio ambiente (sintetizados na palavra tema) e o emprego, por exemplo, de experimentos, de charges e tirinhas ou obras artísticas (sintetizados na palavra usos). Admite-se, contudo, que os itens são mais relevantes do que essa síntese em torno das palavras temas e usos que, uma vez empregadas no questionário, perpetuaram-se na análise. Nesse sentido, também a palavra abordagem não é usada em um sentido estrito e, por fluência do texto, tratou-se, por exemplo, da expressão abordagem experimental ao referir-se ao uso do livro didático para a realização de experimentos.

As respostas eram marcadas pelos estudantes em uma escala de Likert de quatro opções - não me atrai ( $0 \%$ ), me atrai um pouco (33\%), é atrativo (67\%), é muito atrativo (100\%) - sobre 23 itens: "Situações do cotidiano (atravessar a rua, se olhar no espelho, comprar lâmpadas)", "Funcionamento de produtos tecnológicos (geladeira, micro-ondas, máquina fotográfica)", "Uso de matérias de jornal e revista", "Uso de charges e tirinhas", "Relações com esportes", "Relações com a natureza e o meio ambiente", "Exercícios mais conceituais", "Discussões sobre origens e impactos de um conceito na sociedade (exemplo: relação máquinas a vapor e revolução industrial, energia-massa e bomba atômica)", "Experimentos fáceis de serem feitos", "Biografias", "Demonstrações de fórmulas", "Relações com o corpo humano e a saúde", "Relações com o contexto histórico", "Uso de obras artísticas (letras de música, poemas, quadros, 
filmes)", "Atividades em grupo", "Exercício do ENEM", "Pesquisas e debates", "Enfoque matemático", "Evolução dos conceitos científicos", "Exercícios de vestibular", "Relações com a sociedade e questões de cidadania", "Conteúdo digital na Internet associado ao livro" e "Sugestão de links"2.

Relatados esses 23 itens, entendidos como as variáveis do estudo, cabe exemplificar como elas foram definidas para fazer parte do questionário. As pesquisas citadas na fundamentação teórica envolviam diversas abordagens, tais como observação de salas de aula, entrevistas com docentes e questionários a discentes. Em Garcia, Garcia e Pivovar (2007), por exemplo, alguns dos sete professores entrevistados afirmaram seu desejo para que situações do cotidiano fossem um tema mais presente nas obras didáticas. Portanto, desse artigo foi extraída, entre outras, a variável "situações do cotidiano", de modo a verificar se tal interesse se estendia para ou não para outros públicos (estudantes) e se era válida para outras localidades. O mesmo foi feito com os demais trabalhos citados.

Sugestões de estudantes, professores, profissionais do mercado editorial e pesquisadores que participaram dos testes-pilotos também foram incorporadas, entendendo-se que a aplicação do questionário em larga escala era um momento rico de levantamento de dados. É o caso, entre outros, da inclusão de "Relações com o corpo humano e a saúde". Livros de Física costumam tratar do assunto ao abordar, por exemplo, os conceitos de pressão (relação com a pressão sanguínea), temperatura (relação com a febre) ou corrente elétrica (choque como efeito fisiológico). Assim, a partir de um interesse editorial, inseriu-se a investigação de se essa relação - que faz sentido ser mais explorada pensandose em uma integração maior das Ciências da Natureza - é valorizada ou não por docentes e discentes.

Ao longo do texto, os 23 itens podem ser agrupados em categorias de modo a fundamentar a análise. Há, por exemplo, diversos gêneros textuais elencados ("Uso de matérias de jornal e revista"; "Charges e tirinhas", "Obras artísticas", incluindo os hipertextos digitais "Conteúdo digital na internet associado ao livro" e "Sugestão de links"). Há itens relativos a formas de abordagens; outros que tratam de tipos de atividades ("Exercício do ENEM", "Exercícios de vestibular", "Exercícios mais conceituais", "Atividades em grupo"e "Pesquisas e debates"). Há, também, itens relativos a diferentes abordagens pedagógicas: cotidiano a partir de "Situações do cotidiano"; Ciência, Tecnologia e Sociedade (CTS) a partir de "Discussões sobre origens e impactos de um conceito na sociedade" e "Relações com a sociedade e questões de cidadania"; História a partir de "Biografias", "Evolução dos conceitos científicos" e "Relações com o contexto histórico" e assim por diante.

$2 \mathrm{O}$ questionário completo está disponível em http://encurtador.com.br/lFGY7. 
Ressalta-se, contudo, que não estão sendo avaliadas diretamente as possíveis abordagens, mas apenas o interesse por elementos que podem fazer parte delas, em um processo de ensino/aprendizagem guiado pelo professor que extrapola do escopo do livro e, ainda mais, do instrumento de pesquisa, que investiga tão somente os interesses dos estudantes sobre elementos do livro didático.

Comentados os itens integrantes do questionário, passa-se aos estratos de pesquisa. As respostas dadas são comparadas entre si de acordo com os seis estratos: sexo, idade (abaixo ou acima da mediana, de 16 anos), uso ou não do livro didático fora das atividades escolares, estudante da rede pública ou privada, região do Brasil e município (capital ou não) onde estuda. As tabelas abaixo mostram a divisão dos respondentes em cada estrato. Como comentado, há proporções que diferem da proporção do Censo Escolar de 2010, como o baixo número de respostas da região Norte e da rede pública de ensino. Isso se deveu a diferentes taxas de resposta entre os estratos, o que pode ter ocorrido, para além de flutuações aleatórias, por conta da dificuldade de acesso à internet de alguns segmentos. $\mathrm{O}$ quanto isso enfraquece ou não a representatividade da amostra é uma questão a ser verificada na comparação com outros trabalhos similares de larga escala.

TABELAS 1 - COMPOSIÇÃO DOS ESTRATOS DA PESQUISA

\begin{tabular}{|c|c|c|c|}
\hline \multicolumn{2}{|l|}{ Sexo } & \multicolumn{2}{|l|}{ Idade } \\
\hline Masculino & $43 \%$ & Até 16 anos & $39 \%$ \\
\hline Feminino & $57 \%$ & Com 16 anos ou mais & $61 \%$ \\
\hline Região & & Rede de ensino & \\
\hline Sul & $20 \%$ & Pública & $52 \%$ \\
\hline Sudeste & $44 \%$ & Particular & $48 \%$ \\
\hline Centro-Oeste & $8 \%$ & & \\
\hline Nordeste & $23 \%$ & & \\
\hline Norte & $5 \%$ & & \\
\hline
\end{tabular}

\begin{tabular}{ll}
\hline \multicolumn{2}{l}{ Município } \\
\hline Capital & $45 \%$ \\
Não capital & $55 \%$ \\
\hline & \\
\hline \multicolumn{2}{l}{ Usa o livro fora das } \\
atividades escolares \\
\hline Sim & $34 \%$ \\
Não & $66 \%$ \\
\hline
\end{tabular}

FONTE: elaborada pelo autor e bolsistas.

Além de critérios gerais, como o etário e regional, um dos estratos de pesquisa diz respeito ao uso do livro didático fora das atividades escolares. Isto é, nos casos em que os estudantes fazem uso do livro para uma atividade não demandada e nem relacionada com a escola. Caso usassem o livro didático para além das atividades escolares requisitadas, os estudantes deviam responder a uma pergunta de resposta aberta para esclarecer em quais situações faziam 
uso do livro. As respostas abertas foram categorizadas, e cerca de um terço dos estudantes usa o livro fora das atividades escolares e, entre eles, $53 \%$ o fazem por curiosidade, interesse ou passatempo. $26 \%$ o fazem para aprender mais ou se adiantar no conteúdo.

Para a inferência estatística, o nível de significância utilizado nos testes foi de $5 \%$. Para o ranqueamento das respostas e a comparação entre as subdivisões dos estratos foram utilizados os testes de Kruskal-Wallis e Mann-Whitney. A opção por estes testes não paramétricos se dá por não haver respostas em um intervalo de valores contínuos, pois o respondente apenas escolhia entre as opções fornecidas de percentual. Assim, apesar de grande quantidade de respostas, não foi satisfeito o critério de gaussianeidade para aplicação de testes paramétricos (MOOD, GRAYBILL; BOES, 1974; SIEGEL; CASTELLAN, 2006). Todos os cálculos foram realizados no software Minitab 14.

Como estudo exploratório, esta investigação procurou contribuir com possíveis questões e ensaiar hipóteses explicativas iniciais, mas ainda de caráter muito preliminar, a ser trabalhadas em futuras pesquisas. Afinal, entende-se que a riqueza de um estudo exploratório está justamente em sua capacidade de gerar uma série de perguntas e hipóteses para o campo de pesquisa a partir da descrição ampla do cenário em que se encontra o objeto de estudo.

\section{Resultados e discussões}

\section{Temas e usos de interesse - resultado geral}

As respostas dos estudantes permitem organizar a ordem de interesse de certos temas para o livro didático de Física. A Figura 1, a seguir, mostra essa hierarquia nas respostas, com os valores correspondendo à média das respostas dadas para o interesse dos alunos, na escala em que $0 \%$ significa nenhum interesse, e $100 \%$, total interesse.

Não há nenhum quesito com elevada importância (acima de 70\%) e apenas um, as biografias, com interesse abaixo de 50\%. Ademais, há um interesse moderadamente alto pelos itens elencados.

Fazendo uso do teste de Mann-Whitney para hierarquizar as respostas, é possível identificar diferenças estatisticamente significativas entre elas. Essas diferenças estão representadas no gráfico pelo uso de diferentes cores. Assim, 
cores iguais das barras indicam agrupamentos em que as respostas estão em empate técnico, sem poder se afirmar que são estatisticamente diferentes. Por exemplo, o item "Exercícios de vestibular" (69,4\%), em cor azul clara, é estatisticamente diferente do item "Demonstração de fórmulas" (63,8\%), que não contém a cor azul clara $(p$-value $=0,0340)$. Mas o item "Exercícios de vestibular" está tecnicamente empatado com o item "Experimentos simples" $(67,1 \%)(p$-value $=0,4955)$, por isso ambos contêm a cor azul clara. Do mesmo modo, o interesse pelas "Atividades em grupo" $(51,0 \%)$ é estatisticamente diferente ao interesse por "Biografias" $(39,1 \%)(p$-value $=0,0000)$, por isso, eles têm cores diferentes. "Atividades em grupo" também é significativamente diferente do interesse por "Tirinhas e charges" $(59,9 \%)(p$-value $=0,0014)$, por isso, eles não têm cores coincidentes no gráfico. Mas não há diferença estatisticamente significativa entre "Atividades em grupo" e os demais itens de cor marrom, como "Contexto histórico da Ciência" (52,5\%) ( $p$-value $=0,5852)$.

Como evidencia o uso das cores na tentativa de agrupar os quesitos, há vários casos de igualdade estatística, principalmente em razão da alta concentração dos quesitos na faixa de interesse de $50 \%$ a $70 \%$, o que provoca algumas sobreposições dos grupos. Contudo, o teste de hipótese de MannWhitney oferece elementos para uma proposta de análise dos dados a partir de quatro agrupamentos de interesse, ainda que possam haver alguns casos de diferenças não significativas entre eles. São eles: o conjunto de mais alto interesse, dos exercícios de vestibular a experimentos simples (valoração acima de $65 \%$ ), que não contém itens de cor amarela; um segundo grupo de relações com o corpo humano e a saúde ao uso de tirinhas e charges (entre $64 \%$ e $60 \%$ de importância), com todos os itens significativamente iguais de cor amarela; um terceiro grupo que abrange de conteúdo digital a atividades em grupo (entre $59 \%$ e $50 \%$ ), com todos os itens iguais de cor marrom e, por fim, no mais baixo nível de interesse, o item Biografias, com relevância de 39\%. 
FIGURA 1 - TEMAS E USOS DE INTERESSE DOS ESTUDANTES EM ORDEM DECRESCENTE

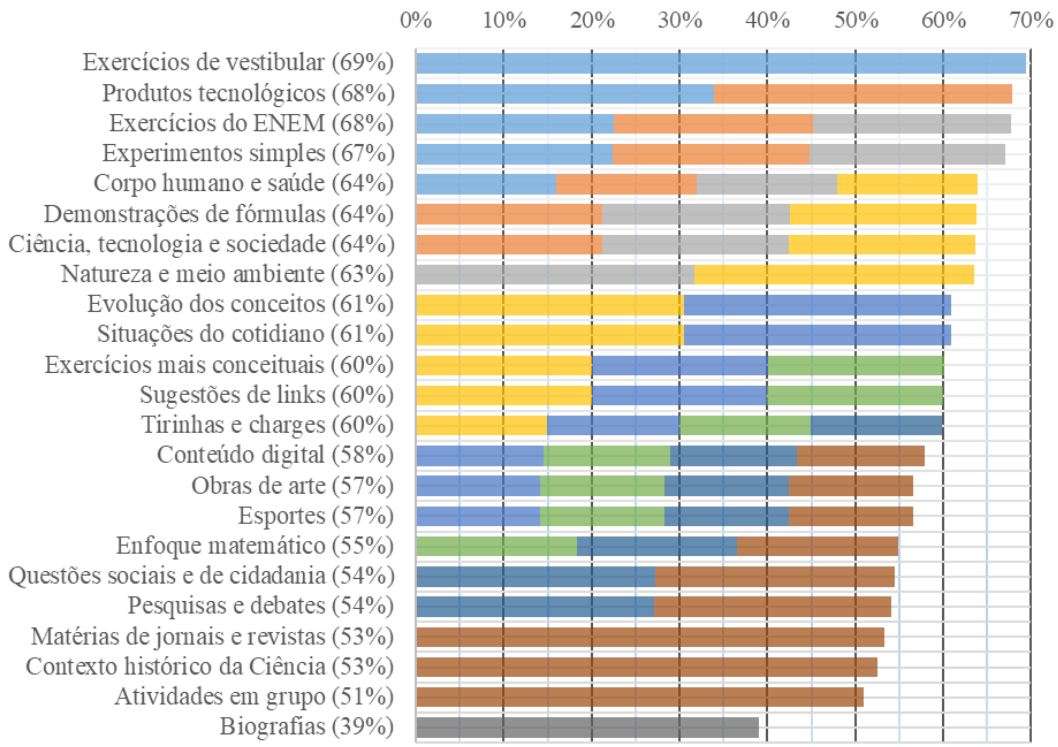

FONTE: elaborada pelo autor e bolsistas.

No primeiro grupo, há os exercícios voltados para a admissão no ensino superior, seja via vestibular $(69,4 \%)$ ou $\operatorname{ENEM}(67,8 \%)$ e dois itens de interesse relativamente alto: experimentos simples $(67,1 \%)$ e o funcionamento de produtos tecnológicos $(67,8 \%)$, tais como geladeiras, fornos de micro-ondas e máquinas fotográficas. Esses dois temas remetem, aparentemente, ao desejo dos estudantes pela relação dos conteúdos físicos com vivências concretas experimentais ou do cotidiano, caso dos produtos tecnológicos. Pelas respostas dos estudantes, para além dos exercícios visando o acesso ao Ensino Superior, são essas as duas das melhores formas de atrair o interesse deles para a Física, o que pode ser aproveitado tanto pelos professores quanto pelos autores e editores de materiais didáticos.

Professores já haviam destacado o efeito positivo de experimentos nos trabalhos de Carneiro, Santos e Mól (2005), Garcia (2009) e Garcia, Garcia e Pivovar (2007). No entanto, em Dias da Silva e Portela (2018) houve uma baixa valorização dos experimentos por parte dos estudantes de Paranaguá/PR, ainda que esse possa ser um efeito localizado não expansível para todo o território 
nacional. O vestibular ter muito apelo no interesse discente é parte do senso comum, mas também tem respaldo em levantamentos científicos anteriores (DIAS DA SILVA; PORTELA, 2018).

O segundo grupo de interesse também concentra temas passíveis de contextualização, como saúde e corpo humano $(63,9 \%)$; impactos e interrelações entre ciência, tecnologia e sociedade $(63,7 \%)$; natureza e meio ambiente (63,5\%); mudanças históricas dos conceitos físicos $(61,0 \%)$; e situações do cotidiano $(60,9 \%)$. Ao menos preliminarmente, pode-se supor que a ênfase na contextualização presente nos documentos oficiais e nas pesquisas da área de ensino e educação encontra ressonância nos anseios discentes. Para os professores com mais tempo de sala aula investigados por Garcia (2009) e Garcia, Garcia e Pivovar (2007), a presença de situações cotidianas no livro didático de fato era um anseio para despertar o interesse dos estudantes, assim como a discussão do processo de construção dos conhecimentos científicos e o enfoque mais conceitual. Também no contexto internacional, os exemplos do cotidiano estão entre os aspectos mais valorizados pelos estudantes (DAKE, 2007). Tal resultado, entretanto, difere do encontrado por Dias da Silva e Portela (2018), em que a abordagem do cotidiano foi pouco valorizada pelos discentes. Talvez essa seja uma característica dos estudantes das escolas de Paranaguá pesquisadas pelas autoras, mas também pode indicar falhas na amostragem da presente pesquisa caso mais pesquisas, em diferentes locais, também apresentem o cotidiano como pouco valorizado pelos estudantes.

A presença dos exercícios conceituais $(60,1 \%)$ nesse segundo grupo de interesse se alinha com uma abordagem de física mais próxima do cotidiano, discussões do campo CTS e tratamento histórico dos conhecimentos científicos, embora também possa indicar uma filiação ao ENEM e aos vestibulares que optaram por uma linha mais conceitual. Destaca-se, ainda, a vontade dos estudantes pela demonstração de fórmulas $(63,8 \%)$, o que pode indicar certa aversão à apresentação tradicional dos modelos matemáticos como prontos e definitivos, preferindo-se a explicitação dos passos que originaram as fórmulas. Claro que esse item também pode remeter a um desejo por maior matematização do conteúdo físico, ao se focar na manipulação algébrica de equações, na contramão do argumentado anteriormente sobre o desejo estudantil de reconhecer e a aplicar os conhecimentos físicos de modo mais conceitual no cotidiano. Contudo, essa matematização pura e simples não parece ser o caso, visto que o enfoque matemático - item pertencente ao terceiro grupo com valoração de $54,9 \%$ - tem interesse significativamente menor do que a demonstração de fórmula. Além disso, os outros quesitos desse segundo conjunto parecem apontar mais no sentido de uma curiosidade $\mathrm{e}$ compreensão ampla da realidade e do conhecimento científico do que uma visão 
puramente matemática. Nessa proposta de interpretação, trata-se, portanto, de uma vontade de se conhecer de onde e como surgem os modelos matemáticos, inclusive relacionando-os com o cotidiano, os produtos tecnológicos, o corpo humano, etc. - e não manipulá-los apenas como um fim em si mesmo. Caso seja de fato esse o entendimento dos estudantes, ele estará em consonância com o argumentado pelos professores na investigação de Carneiro, Santos e Mól (2005), que veem como positiva a diversidade de temas do cotidiano nas obras didáticas, e também com a argumentação de Wuo (2002) de materiais que propiciem uma aprendizagem mais criativa.

Fechando o segundo grupo, há quesitos que dizem respeito a gêneros textuais: as sugestões de links $(60 \%)$ e o uso de tirinhas e charges $(60 \%)$. No primeiro caso, uma hipótese que pode ser investigada com maior profundidade é quanto ao aprofundamento ou expansão do material para além das páginas do livro, fazendo uso de uma tecnologia digital de comunicação tipicamente associada às novas gerações. Tal interesse não foi verificado como importante por Dake (2007) e Nogova (2011) no cenário internacional, mas pode tanto representar uma preferência nacional, como também indicar uma mudança dos tempos, visto que os trabalhos citados trabalharam com dados levantados cerca de cinco anos antes aos da presente pesquisa.

O uso de tirinhas e charges - imagens capazes de dizer muito com poucas palavras - pode apontar para a preferência de linguagem desejada pelos estudantes, que lembra a linguagem e os memes das redes sociais. Contribuindo para essa reflexão, as pesquisas nacionais de Megid Neto e Fracalanza (2003), Mello (2013) e Dias da Silva e Portela (2018) indicam uma preferência dos alunos e docentes brasileiros por uma mais linguagem direta, clara e concisa, por vezes ligada às imagens. Todavia, as tirinhas e charges não necessariamente são claras e diretas, embora sejam concisas. Muitas vezes, elas fazem uso de metáforas e exigem conhecimentos prévios que não tornam a linguagem tão clara e direta assim para quem não tem o poder analítico e o conhecimento prévio necessário para lê-las. Mas o que emerge dessa preferência alegada pelos estudantes é uma linguagem multimodal, na qual o hipertexto, a imagem e o texto escrito típico são gêneros presentes.

O terceiro grupo, de relevância moderada, engloba menos temas passíveis de contextualização que os anteriores, inclusive demonstrando um menor interesse por esportes $(56,5 \%)$, em contraste com o estereótipo brasileiro de valorizar esse tema. Também contrastando com expectativas comuns, o conteúdo digital não é tão valorizado $(57,9 \%)$, aparecendo apenas nesse terceiro agrupamento de importância. Ainda nesse conjunto estão alguns possíveis focos para as atividades, como o enfoque matemático $(54,9 \%)$, as pesquisas e os debates $(54,1 \%)$ e os trabalhos em grupo $(51,0 \%)$ - todos menos valorizados que 
os exercícios conceituais $(60,1 \%)$ e muito menos que os de vestibular $(69,4 \%)$ e ENEM (67,8\%). Embora pesquisas, debates e atividades em grupo sejam incentivados pelas investigações da área em busca de um ensino mais coletivo e reflexivo, inclusive pela capacidade de colocar os estudantes em posições mais ativas e desenvolver capacidades diversas do domínio de conteúdos puramente conceituais, os alunos não demonstram grande interesse na perspectiva procedimental, atitudinal e socioafetiva possibilitada por essas atividades.

Nesse grupo de menor relevância, também aparecem mais algumas formas de gênero textual: o uso de obras artísticas $(56,5 \%)$ - como letras de música, poemas, quadros e filmes - e as notícias de jornais e revistas $(53,3 \%)$, indicando que talvez a variação de gêneros textuais em um livro didático não seja uma prioridade para os discentes. Inclusive, esse resultado difere da opinião dos professores, investigada por Carneiro, Santos e Mól (2005), que apontava, a partir do relato dos docentes, para um suposto interesse dos alunos por livros didáticos que se aproximassem de revistas, embora os respondentes pudessem estar se referindo ao formato e ao design de uma revista, não à sua linguagem e conteúdo. Contudo, além dos públicos diferentes, também é necessário salvaguardar possíveis diferenças temporais, de cerca de 10 anos, entre os estudos. Mais uma consideração é que a pesquisa de Carneiro, Santos e Mól (2005) foi realizada com professores, e nem sempre o que os respondentes relatam corresponde ao que efetivamente fazem e valorizam, e o levantamento de dados é ainda mais indireto quando se referem a outro público (no caso, docentes se referindo a estudantes).

Outro complicador desse resultado de interesse sobre obras artísticas e notícias de mídia impressa é que as questões do ENEM e muitos vestibulares se utilizam fartamente desses textos, e ambos, ENEM e vestibulares, estão entre as prioridades dos estudantes quanto aos livros didáticos (interesse em torno de $70 \%$ ), ao contrário desses gêneros textuais (interesse em torno de $55 \%$ ). Isso pode ensejar o argumento de que os resultados da pesquisa revelam indicativos indiretos sobre como os livros didáticos vêm sendo utilizados em sala de aula (manifestados nos "interesses" dos estudantes). Ao serem usados como repositórios de exercícios, com especial destaque para os provenientes do ENEM e de vestibulares, torna-se esse o maior interesse dos estudantes. A partir dessa forma de inserção do livro na cultura escolar, pode-se argumentar que esse é o motivo de os estudantes não valorizarem da mesma maneira o uso de obras artísticas e notícias midiáticas fora dos exercícios, ainda que os gêneros textuais sejam subsídios para a realização futura dessas questões.

Por fim, mas ainda no mesmo grupo, questões relacionadas com a cidadania $(54,5 \%)$ elementos de uma visão mais externalista da história da ciência, discutindo o contexto de surgimento das teorias científicas $(52,5 \%)$, 
também não estão entre as prioridades dos alunos. Nessa divisão de abordagem internalista e externalista da história da ciência, considerou-se que a evolução dos conceitos e o contexto histórico da Ciência comporiam elementos de uma visão mais externalista, enquanto as biografias tratariam de elementos de uma visão mais internalista da história. Entre professores, a abordagem CTS e o tema do contexto histórico também é controverso (CARNEIRO; SANTOS; MÓL, 2005). Todavia, a relevância de elementos relacionados com a história externalista ainda é significativamente superior aos elementos da visão internalista, visto que as biografias têm apenas $39,1 \%$ de interesse, sendo sensivelmente menos valorizadas pelos estudantes do que qualquer outro item pesquisado do livro didático.

\section{Temas do livro didático - diferenças nos subgrupos}

Não houve análise de subgrupos de respostas acerca de temas do livro de Física em nenhuma das bibliografias pesquisadas, exceto em Mello (2013). A pesquisadora investigou diferenças entre estudantes de escolas públicas e privadas, mas, para além desse caso, as discussões aqui apresentadas são possivelmente inéditas no campo de pesquisa.

Entre os seis estratos investigados - sexo, idade, rede de ensino, região do país, município e uso do livro fora das atividades escolares -, apenas a região não apresentou nenhum caso estatisticamente significativo entre os 23 temas pesquisados. As diferenças constatadas nos demais subgrupos serão explicitadas, contudo, não foram muitos os casos significativos, indicando certa homogeneidade no interesse pelos livros didáticos de Física.

a. Sexo - Houve diferença estatística em cinco casos: "Funcionamento de produtos tecnológicos", "Discussões sobre origens e impactos de um conceito na sociedade", "Uso de obras artísticas", "Enfoque matemático", e "Evolução dos conceitos científicos". Com exceção das obras de arte, todos os outros elementos citados foram avaliados como mais interessantes por parte de estudantes do sexo masculino, como mostra a Figura 2. 
FIGURA 2 - DIFERENÇAS DE TEMAS E USOS DE INTERESSE DE ACORDO COM O SEXO DOS ESTUDANTES

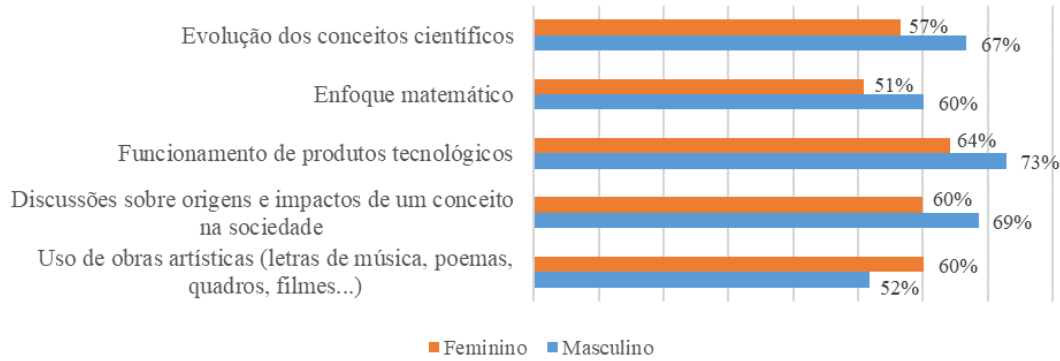

FONTE: elaborada pelo autor e bolsistas.

Análises em relação ao sexo necessitam de muito cuidado e experiência para não ser reduzidas a estereótipos prejudiciais, também, ao próprio campo de investigação científica. Portanto, para se compreender os motivos dos resultados encontrados, são fundamentais novas e aprofundadas pesquisas atentas às discussões atuais dos estudos de sexo e gênero. A hegemonia de uma representação de uma ciência masculina, branca e europeia poderia estar relacionada com isso. Por ora, há apenas a indicação da preferência masculina pelo tema da tecnologia e por abordagens que levem em conta uma maior matematização, mas também elementos da história da ciência. Considerando-se também os resultados de Artuso et al. (2019), em que se identificou que muitas imagens, conteúdo digital e resumos e esquemas foram mais relevantes para as alunas, a preferência maior delas pelo uso de letras de música, poemas, pinturas, esculturas, etc. pode indicar que as estudantes estão mais interessadas em uma obra com mais variações visuais, com texto mais dinâmico e imagético. Aparentemente há uma divisão na preferência de linguagem, mais matematizada para estudantes do sexo masculino e mais multimodal para as estudantes do sexo feminino. Novamente, são apenas inferências iniciais que precisam ser aprofundadas em novas e específicas investigações.

b. Idade - Foram sete os casos de diferença estatística: "Uso de matérias de jornal e revista", "Relações com a natureza e o meio ambiente", "Discussões sobre origens e impactos de um conceito na sociedade ", "Relações com o contexto histórico", "Atividades em grupo", "Enfoque matemático", e "Exercícios de vestibular". Exceto no quesito das atividades em grupo, todos os demais itens foram mais valorizados pela metade mais velha de estudantes respondentes, com idade igual ou superior a 16. A Figura 3 indica esses casos que apresentaram diferenças significativas. 
FIGURA 3 - DIFERENÇAS DE TEMAS E USOS DE INTERESSE DE ACORDO COM A IDADE DOS ESTUDANTES

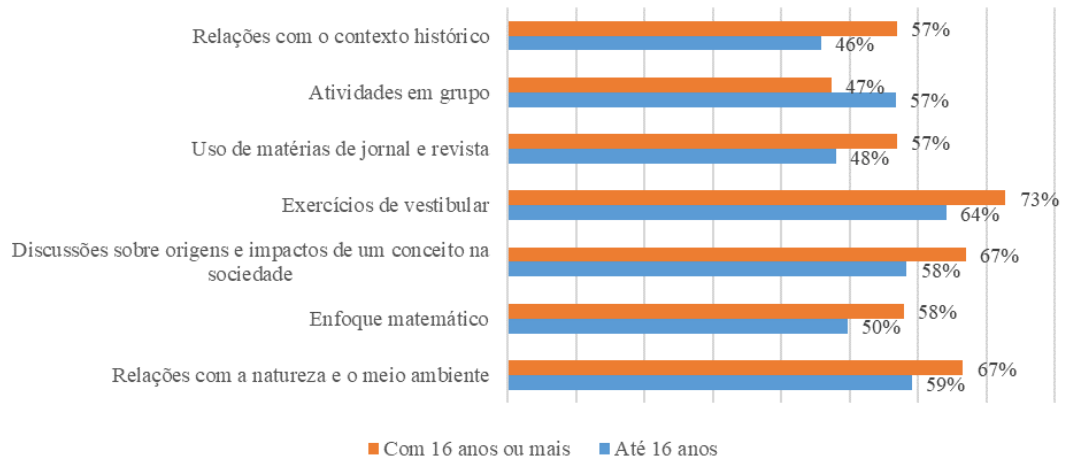

FONTE: elaborada pelo autor e bolsistas.

Aceitando-se o pressuposto de que estudantes mais velhos se preocupam mais com o ingresso no ensino superior, é fácil compreender o interesse deles ser maior por exercícios de vestibular e, pensando-se nos exames mais tradicionais, também no enfoque matemático. Por outro lado, mostram certa atenção a possíveis relações e impactos dos conceitos científicos na sociedade e no meio ambiente, além de valorizarem uma história da ciência externalista que discute as condições e contextos de produção dos conhecimentos científicos. No entanto, essa preocupação socioambiental pode contrastar com o fato de eles não valorizarem as atividades coletivas tanto quanto os estudantes mais novos. Entre as hipóteses para compatibilizar esses resultados, pode-se atribui-los a uma maior maturidade social dos estudantes mais velhos, mas que, sem experiências positivas com trabalhos em grupo, não percebem nessas atividades vantagens pedagógicas ou para o convívio social. Tal resultado pode, inclusive, ser usado para se repensar as atividades coletivas de Física no Ensino Médio de modo a não gerar a aversão a elas com o decorrer dos anos.

c. Rede de ensino público ou privado - Os temas e usos de interesse dos estudantes da rede pública ou particular difere estatisticamente em apenas três casos: "Situações do cotidiano" (66\% na rede privada x 57\% na pública), "Biografias" (35\% na rede privada x 43\% na pública), e "Evolução dos conceitos científicos" (57\% na rede privada x $65 \%$ na pública).

Os exemplos dados para as situações do cotidiano - atravessar a rua, se olhar no espelho, comprar lâmpadas - remetem a cobranças típicas do ENEM, indicando que uma hipótese explicativa inicial para esse resultado pode ser 
a preocupação com o acesso ao ensino superior, supostamente maior na rede particular (MOETO; PEREIRA; MENEZES, 2017). Já a curiosidade histórica, ainda que com o viés internalista dos nomes famosos e suas biografias, é superior entre estudantes da escola pública, resultado similar ao encontrado por Mello (2013). O quanto isso pode estar ligado a uma vontade deles de compreender e eventualmente alterar o lugar histórico ocupado pelos conceitos físicos ou por personagens de destaque é uma questão que pesquisas de viés mais antropológico podem ajudar a desvendar. De todo modo, o resultado contrasta com o senso comum de maior acomodação dos estudantes da rede pública diante do interesse pela Física.

Ao contrário de Mello (2013), que encontrou um baixo interesse por experimentos na rede privada em comparação com a rede pública, a presente pesquisa não identificou diferença estatisticamente significativa nesse quesito (66\% na rede privada $\mathrm{x} 68 \%$ na pública)

d. Município - Apenas um caso significativo foi registrado: "Experimentos fáceis de serem feitos", que são mais valorizados por estudantes que não habitam em capitais ( $72 \%$ x $60 \%$ dos estudantes de capitais). Uma possível explicação está na infraestrutura das escolas que não se situam em capitais, tipicamente os maiores centros urbanos dos estados e com as escolas mais bem equipadas. Nessa linha de raciocínio, sem laboratórios de qualidade nas próprias escolas, os estudantes de fora das capitais tendem a se interessar mais por experimentos fáceis que eles próprios possam realizar.

e. Usa o livro fora das atividades escolares - Entre os subgrupos analisados, esse é o que mais apresenta diferenças no interesse pelo livro didático de Física, pois foram encontradas desigualdades em 12 dos 23 casos investigados, conforme consta na Figura 4. Não há, entretanto, a identificação de um padrão nesses quesitos. Eles tratam de gêneros textuais ("Uso de matérias de jornal e revista"), incluindo os digitais ("Conteúdo digital na internet associado ao livro" e "sugestão de links"); abordagens históricas ("Biografias", "Evolução dos conceitos científicos" e "Relações com o contexto histórico"); tipos de atividades ("Exercícios mais conceituais" e "Pesquisas e debates"); abordagem matemática e enfoque CTS e de cidadania. Apenas entre os temas passíveis de contextualização e exemplificação é que parece haver igualdade nesse estrato, exceto pelo item "Corpo humano e saúde". Esportes, cotidiano, tecnologia e natureza e meio ambiente são outros exemplos de temas constantes no questionário, mas que não se mostraram diferentes nesse subgrupo de análise. 
FIGURA 4 - DIFERENÇAS DOS INTERESSES DE ACORDO COM O USO DO LIVRO (LD) FORA DAS ATIVIDADES ESCOLARES

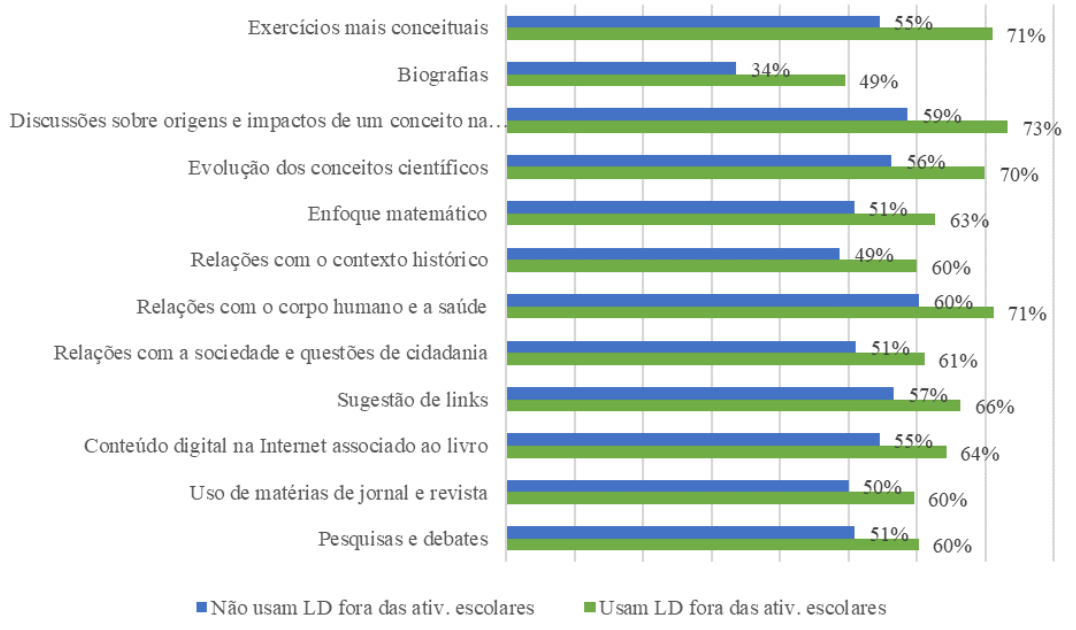

FONTE: elaborada pelo autor e bolsistas.

Os estudantes que utilizam o livro didático fora das atividades escolares requisitadas pelos professores - por exemplo, para aprender mais ou simplesmente por curiosidade ou passatempo - demonstram sempre maior interesse do que os demais discentes. Tal resultado é esperado se considerarmos que aquele subgrupo tende a ter um envolvimento com a Física ou uma curiosidade científica superior aos demais estudantes. Todavia, chama a atenção que esse interesse se volte também para o livro didático, não ficando restrito a buscas em outras mídias, como jornais, revistas e livros de divulgação científica, especialmente as acessíveis em formato digital pela Internet. Nessa linha de raciocínio, o PNLD se mostra particularmente valioso para dar acesso gratuito a livros a um público que talvez tivesse dificuldade em acessá-lo de outra maneira. O PNLD pode estar levando exemplares à casa de milhões de brasileiros que não contavam com livros em seu cotidiano e que eventualmente reconhecem nas obras aprovadas pelo MEC uma fonte segura de informação e uma possibilidade de satisfazer suas curiosidades. Desse modo, pode-se inclusive refletir sobre a ampliação do programa para abarcar também obras de outra natureza com distribuição gratuita e individual, como os livros de divulgação científica e paradidáticos. 


\section{Considerações finais}

Visando contribuir com o campo de pesquisa em livros didáticos e de Ensino de Física, mas também com a política pública de avaliação e distribuição dos livros didáticos por meio do PNLD e com o trabalho de autores e editores de materiais didáticos, investigou-se os temas mais valorizados pelos secundaristas no livro didático de Física. Há, claro, limites na pesquisa, como o fato de ter somente investigado o interesse alegado pelos estudantes. Como os usos ocorrem de fato em sala de aula e como o livro didático é (ou não) explorado pelo professor não é alvo de discussão, e os resultados obtidos devem ser ponderados à luz dessa limitação.

Outra limitação é que a avaliação dos livros didáticos pelos estudantes respondentes não mede seus interesses de maneira neutra em relação aos usos a que estão submetidos em sua cultura e história escolares. Como parte da cultura escolar, artefato multifacetado e integrante do mercado, o livro didático não pode ser isolado dessas dimensões, e nem as respostas dos estudantes ser dissociadas delas. Logo, os interesses declarados pelos discentes devem ser contextualizados dentro dessa lógica de usos e expectativas do livro didático que permeiam a cultura e a economia

Em trabalho anterior (ARTUSO et al., 2019), os estudantes brasileiros declararam ser de grande importância os livros de Física despertarem seus interesses. Entre 14 itens, tal desejo só era menor ao de se ter livros sem erros conceituais e com resumos. Resultado similar também foi identificado por Megid Neto e Fracalanza (2003), Carneiro, Santos e Mól (2005), em pesquisa com professores, e Dias da Silva e Portela (2018). Como instigar esse interesse, no entanto, era uma lacuna em pesquisas nacionais de larga escala com a qual a presente investigação procurou contribuir.

De acordo com as respostas dos discentes, há dois grupos de temas com maior potencial para motivá-los. O primeiro é abordar o funcionamento de produtos tecnológicos, a proposição de experimentos fáceis de ser realizados e, principalmente, a presença de exercícios de vestibular e ENEM - com um nível de interesse próximo a 70\%. Em segundo lugar, em um bloco de interesse entre $60 \%$ e $64 \%$, estão as relações da Física com o corpo humano e a saúde, com a natureza e o meio ambiente, com as situações do cotidiano (como atravessar uma rua, se olhar no espelho ou comprar lâmpadas) e elementos de uma possível abordagem CTS que discuta origens e impactos de conceitos científicos na sociedade, como a relação de máquinas a vapor e revolução industrial ou do conceito de equivalência massa-energia e o desenvolvimento e uso de armas 
nucleares. Contudo, não desperta tanto interesse elementos de uma abordagem CTS mais relacionada com o exercício da cidadania, como discussões políticas relativas à produção de energia ou à finalidade da base de Alcântara, para citar algumas possibilidades.

Quanto ao interesse por elementos da abordagem da História da Ciência, os estudantes demonstram maior interesse nas transformações dos conceitos físicos com o tempo ( $61 \%$ de interesse), acima do interesse pelo contexto histórico dos desenvolvimentos científicos (53\%) e bastante superior às biografias $(39 \%)$, elemento típico de abordagens mais internalistas. Contudo, os estudantes não declararam tanto entusiasmo aos itens relativos à História da Ciência como aos relativos a produtos tecnológicos ou experimentação.

Também não estão entre as prioridades dos estudantes (interesse entre $53 \%$ e $58 \%$ ) as variações de mídia e de gêneros textuais apresentados no livro didático, como conteúdo digital, uso de charges, tirinhas, letras de música, poemas, quadros, filmes e matérias de jornal e revista.

Tais resultados gerais apontam para algumas possíveis consequências e desafios, especialmente nos âmbitos acadêmico, político e editorial. Academicamente, tem-se a constatação do interesse por uma abordagem experimental, que já vem sendo defendida pelos trabalhos acadêmicos há pelo menos 30 anos. Também se vê surgir o interesse para o enfoque CTS, especialmente pelo viés de produtos tecnológicos, que pode ser ampliado para uma discussão de, por exemplo, quais mudanças nas relações sociais e históricas permitiram o surgimento de tais produtos tecnológicos ou foram causadas por eles ou quais são os debates contemporâneos relacionados com o desenvolvimento, uso e consumo desses produtos. Desenvolver teorias de ensino e produtos educacionais adequados a essas abordagens é um dos possíveis caminhos de investigação científica. Há também um desafio no que diz respeito à linguagem das obras e ao papel da Matemática nos livros de Física. Em especial no uso de teorias e no desenvolvimento de práticas didáticas sobre como balancear uma linguagem de fácil acesso, mas também rigorosa e matemática; concisa, mas não superficial; imagética, mas também verbal e capaz de despertar interesse e atribuir sentido ao o que estudantes estão aprendendo, aliando aplicações práticas e imediatas com a necessidade de abstração característica da Ciência.

Editorialmente, tem-se o desafio de produzir em larga escala materiais didáticos mais apropriados para o interesse estudantil, com a vantagem de que este pouco varia geograficamente. Sinteticamente, tais materiais partiriam de elementos possíveis de serem utilizados em abordagens experimentais e CTS, teriam como temas de contextualização os produtos tecnológicos, o corpo humano, a saúde, a natureza e o meio ambiente. Ainda que atendendo a vestibulares e ao ENEM, isso pode ser feito com um enfoque em exercícios 
mais conceituais aliado a demonstrações de fórmulas quando há necessidade de matematização, aplicações no cotidiano e uso mais extensivo de links, charges e tirinhas. Isso pode ser auxiliado pela incorporação de modo consistente dos achados do campo científico nos materiais didáticos comerciais, como exemplificado pelas três décadas de pesquisa em experimentação, bem como pela aproximação entre profissionais desses dois campos para futuros desenvolvimentos tanto de trabalhos editoriais quanto científicos.

Politicamente, uma contribuição é a de aprimorar os investimentos públicos em materiais escolares e sua efetividade no processo pedagógico ao se levar em conta o interesse dos estudantes. Seria o caso de se incentivar ou viabilizar, via editais públicos, materiais de aprendizagem mais alinhados com os achados do campo científico e, um exemplo concreto, é o de promover o desenvolvimento de cadernos temáticos sobre saúde, tecnologia, corpo humano e meio ambiente. Outro é dar um peso maior a quesitos relativos à abordagem experimental, especialmente a que problematiza a concepção empirista-indutiva da Ciência, e à abordagem CTS na avaliação das coleções didáticas submetidas ao PNLD.

Entretanto, levar em conta o interesse dos estudantes não significa, necessariamente, que as obras didáticas devam se guiar exclusivamente por esses interesses. Afinal, a escola também é espaço de se discutir e trabalhar esses interesses. Ou seja, as cobranças e formas de uso do livro didático também podem ser debatidas e repensadas, já que estas influenciam no que os estudantes manifestam como interesses.

Para além desses resultados gerais, fica em aberto para o campo científico - em especial os estudos de sexo e gênero - a investigação das razões e consequências de por que estudantes do sexo feminino alegam se interessar mais por imagens, conteúdo digital, resumos, esquemas e obras de arte e a preferência masculina se dá por produtos tecnológicos e enfoque matemático.

Outra consequência dos resultados encontrados entre os subgrupos da pesquisa diz respeito ao um terço de estudantes que alega usar o livro didático fora das atividades escolares. Para estes, há uma valorização do livro físico como fonte de informação e entretenimento e a busca espontânea por mais leitura, o que indica uma demanda reprimida por, por exemplo, obras de divulgação científica e materiais paradidáticos que pode ser explorada tanto pelo mercado editorial como pelas políticas públicas operacionalizadas por meio de editais de seleção e aquisição de obras como o PNLD e congêneres.

Em todas essas discussões não se pode tirar do horizonte que o papel assumido pelo livro didático em uma escola não é único, não se dá de modo neutro e nem é exclusivamente determinante do processo pedagógico. Embora não se negue sua relevância e influência, um livro traz consigo interesses políticos, mercadológicos e ideológicos que podem trazer benefícios ou prejuízos 
para o processo pedagógico, que podem ou não conflitar com as políticas públicas educacionais e as realidades locais, tendo maior ou menor potencial de influenciar cada realidade a depender de como é utilizado. Exemplificando, uma obra com muitos experimentos abertos pode chegar a uma escola e encontrar docentes que não dispõem de condições materiais (tempo, equipamentos, laboratórios...), não se sentem confortáveis ou não veem a necessidade de se trabalhar com os estudantes tais atividades experimentais. O que demonstra também a necessidade de investimentos em infraestrutura, formação inicial e continuada dos professores, além de se respeitar à autonomia docente e reconhecer a legitimidade de ações em outras linhas político-pedagógicas fundamentadas.

\section{REFERÊNCIAS}

APPLE, Michael W. Política cultural e educação. 2. ed. São Paulo: Cortez, 2001.

ARTUSO, Alysson R. Para que serve o livro didático de Física? - as respostas dos professores. In: ENCONTRO NACIONAL DE DIDÁTICA E PRÁTICA DE ENSINO, 17., 2014, Fortaleza. Anais [...]. Fortaleza: UFCE, 2014. Disponível em: http:// www.uece.br/endipe2014/ebooks/livro3/372\%20PARA\%20QUE\%20SERVE\%20 O\%20LIVRO \%20DID $\%$ c3\%81TICO\%20DE\%20F\%c3\%8dSICA \%20-\%20AS\%20 RESPOSTAS\%20DOS\%20PROFESSORES.pdf. Acesso em: 20 maio 2020.

ARTUSO, Alysson R. Livro didático digital - o presente, o futuro e as possibilidades do mercado editorial no contexto brasileiro e internacional. Revista de Currículum y Formación del Profesorado, Granada, v. 20, n. 1, p. 171-198, 2016.

ARTUSO, Alysson R.; APPEL, Jeferson L. Diferenças na dinâmica de aula dos professores e sua relação com o livro didático de Física do ensino médio. In: SIMPÓSIO NACIONAL DE ENSINO DE FÍSICA, 21., 2015, Uberlândia. Anais [...]. São Paulo: SBF, 2015. Disponível em: http://www.sbf1.sbfisica.org.br/eventos/snef/xxi/sys/resumos/ T0944-1.pdf. Acesso em: 20 maio 2020.

ARTUSO, Alysson R.; MARTINO, Luiz H.; COSTA, Henrique V.; LIMA, Leticia. Livro didático de Física - quais características os estudantes mais valorizam? Revista Brasileira de Ensino de Física, São Paulo, v. 41, p. 1-16, 2019.

BRASIL. Ministério da Educação. Dados estatísticos. Brasília, DF: Fundo Nacional do Desenvolvimento da Educação, 2019. Disponível em: https://www.fnde.gov.br/index.php/ programas/programas-do-livro/pnld/dados-estatisticos. Acesso em: 31 dez. 2019.

BOLFARINE, Heleno; BUSSAB, Wilton O. Elementos de Amostragem. São Paulo: Edgar Blucher, 2005. 
CARNEIRO, Maria Helena S.; SANTOS, Widson L. P.; MÓL, Gerson S. Livro didático inovador e professores: uma tensão a ser vencida. ENSAIO - Pesquisa em Educação em Ciências, Belo Horizonte, v. 7, n. 2, p. 101-113, 2005.

CASSIANO, Célia C. F. O mercado do livro didático no Brasil do século XXI: a entrada do capital espanhol na educação nacional. São Paulo: UNESP, 2013.

CHOPPIN, Alain. História dos livros e das edições didáticas: sobre o estado da arte. Educação e Pesquisa, São Paulo, v. 30, n. 3, p. 549-566, 2004.

DAKE, Leonard S. Student selection of the Textbook for an Introductory Physics Course. The Pyshics Teacher, Maryland, USA, v. 45, p. 416-419, 2007.

DIAS DA SILVA; Kelly F. V.; PORTELA, Caroline D. P. A visão dos alunos sobre a utilização do livro didático de Física pelo professor. Ciência é minha praia, Paranaguá, v. 5, n. 1, p. 47-56, 2018.

FORQUIN, Jean-Claude. Escola e cultura - as bases sociais e epistemológicas do conhecimento escolar. Porto Alegre: Artmed, 1993.

GARCIA, Tânia Maria F. B. Relações de professores e alunos com os livros didáticos de Física. In: SIMPÓSIO NACIONAL DE ENSINO DE FÍSICA, 18., 2009, Vitória. Anais [...]. São Paulo: SBF, 2009. Disponível em: http://www.sbf1.sbfisica.org.br/eventos/snef/ xviii/sys/resumos/T0724-2.pdf. Acesso em: 17 dez. 2019.

GARCIA, Tânia Maria F. B.; GARCIA, Nilson Marcos D.; PIVOVAR, Luiz Eduardo. O uso do livro didático de Física: estudo sobre a relação dos professores com as orientações metodológicas. In: ENCONTRO NACIONAL DE PESQUISA EM EDUCAÇÃO EM CIÊNCIA, 6., 2007, Florianópolis. Atas [...]. Florianópolis: Abrapec, 2007. Disponível em: http://abrapecnet.org.br/atas_enpec/vienpec/CR2/p1099.pdf. Acesso em: 20 dez. 2019.

GRESSLER, Lori Alice. Introdução à pesquisa. São Paulo: Loyola, 2004.

LEITE, Álvaro Emílio; GARCIA, Nilson Marcos D. Funções dos livros didáticos e a formação de professores de Física. In: GARCIA, Nilson Marcos D. Garcia (org.). O livro didático de Física e de Ciências em foco: dez anos de pesquisa. São Paulo: Livraria da Física, 2017.

MARTINS, Alisson Antonio; GARCIA, Nilson Marcos D. Artefato da cultura escolar ou mercadoria? A escolha do livro didático de Física em análise. Educar em Revista, Curitiba, v. 35, n. 74, p. 173-192, 2019.

MEGID NETO, Jorge; FRACALANZA, Hilário. O livro didático de ciências: problemas e soluções. Ciência \& Educação, Bauru, v. 9, n. 2, p. 147-157, 2003.

MELLO, Ana Caroline. A percepção de alunos sobre o papel e o uso do livro didático de Física no ensino médio. Trabalho de Conclusão de Curso (Licenciatura em Física) Universidade Tecnológica Federal do Paraná, Curitiba, 2013. 
MOETO, Cecília B.; PEREIRA, Isabela L.; MENEZES, Paulo Henrique D. A influência dos processos seletivos das universidades sobre os currículos de física da escola básica: estudo comparativo entre questões de Física do ENEM e de um programa de ingresso em universidade pública. In: ENCONTRO NACIONAL DE PESQUISA EM EDUCAÇÃO EM CIÊNCIAS, 11., 2017, Florianópolis. Atas [...]. Florianópolis: Abrapec, 2017. Disponível em: http://www.abrapecnet.org.br/enpec/xi-enpec/anais/resumos/R0649-1. pdf. Acesso em: 15 dez. 2019.

MOOD, Alexander M., GRAYBILL, Franklin A.; BOES, Duane C. Introduction to the Theory of Statistics. 3. ed. New York: McGraw-Hill, 1974.

MUNAKATA, Kazumi. O livro didático como mercadoria. Pro-Posições, Campinas, v. 23, n. 3, p. 51-66, 2012.

NOGOVA, Mikaella. Which learning media do students prefer? In: INTERNATIONAL CONFERENCE ON RESEARCH ON TEXTBOOKS AND EDUCATIONAL MEDIA, 11., 2011, Kaunas, Lithuania. Proceedings... Kaunas, Lithuania: IARTEM, 2011.

SIEGEL, Sidney; CASTELLAN JR., N. John. Estatística não-paramétrica para ciências do comportamento. 2. ed. Porto Alegre: Artmed, 2006. (Métodos de Pesquisa).

WUO, Wagner. O ensino de Física: saber científico, livros e prática docente. In: BUENO, José Geraldo Silveira (org.). Escolarização, práticas didáticas, controle e organização do ensino. Araraquara: J. M. Editores, 2002.

Texto recebido em 31/12/2019.

Texto aceito em 29/05/2020. 